\title{
BMJ Open Conversion therapies and access to transition-related healthcare in transgender people: a narrative systematic review
}

\author{
Talen Wright, ${ }^{1}$ Bridget Candy, ${ }^{2}$ Michael King ${ }^{1}$
}

To cite: Wright T, Candy B, King M. Conversion therapies and access to transitionrelated healthcare in transgender people: a narrative systematic review. BMJ Open 2018;8:e022425. doi:10.1136/ bmjopen-2018-022425

- Prepublication history for this paper is available online. To view these files, please visit the journal online (http://dx.doi. org/10.1136/bmjopen-2018022425).

Received 19 February 2018 Revised 16 August 2018 Accepted 18 October 2018
Check for updates

(C) Author(s) (or their employer(s)) 2018. Re-use permitted under CC BY-NC. No commercial re-use. See rights and permissions. Published by BMJ.

${ }^{1}$ Division of Psychiatry, University College London, London, London, UK

${ }^{2}$ Marie Curie Palliative Care

Research Department, Division of Psychiatry, University College London, London, UK

Correspondence to

Dr Bridget Candy;

b.candy@ucl.ac.uk

\section{ABSTRACT}

Objectives Conversion is a term for treatments that seek to suppress or change a person's sexual orientation or gender. Our review focuses on transgender and genderdiverse (TGD) people. Our aims were to (1) describe the frequency, nature and structure of conversion practices; (2) document difficulties in accessing transitionrelated healthcare and (3) evaluate the mental health consequences of such practices and access barriers. Method Systematic review and narrative synthesis using the Critical Appraisals Skills Programme and Joanne Briggs Institute critical appraisal tools. Data sources include Embase, MEDLINE, PsychINF0, PsychARTICLES and Web of Science between 1990 and June 2017. Participants Studies were included that (1) document use of conversion therapies or access barriers to transition-related healthcare; and/or (2) describe how such therapeutic practices and access barriers have been applied and/or (3) evaluate the mental health impacts of such therapies and difficulties accessing transition-related healthcare. Two reviewers screened papers for eligibility. Data were then grouped according to the objectives. Narratives and themes were presented per study.

Results Seven studies met inclusion criteria. Four reports were on 'realignment', involving case studies or case series. Two involved psychoanalysis, one self-exposure therapy and one open-ended play psychotherapy. All four studies concerning 'realignment' were of poor methodological quality. The other three studies explored access barriers from the view point of TGD youth, their parents and healthcare providers. All papers reported access barriers, such as inability to access pubertydelaying medications. The papers concerning barriers to access were of good methodological quality. Conclusion We found limited published evidence on use, nature, structure and/or health consequences of conversion therapies and access barriers to transition in TGD people. However, reports of restriction to access may indicate a more widespread problem. Research is needed into TGD people's experiences of conversion therapy and access barriers to transition-related healthcare Trial registration number CRD42017062149.

\section{INTRODUCTION}

Transgender and gender diverse (TGD) is an umbrella term for people whose gender
Strengths and limitations of this study

- Rigorous systematic review methods, including searching five databases.

- Brings attention to under-researched field of transgender and gender-diverse health.

- Lack of inclusion of grey literature.

- Challenges in study identification because conversion therapies and access barriers can be variously described.

- Lack of reach into educational or religious establishments.

differs from that normatively expected of their assigned sex or with the binary conception of gender that is common to most cultures. ${ }^{1}$ It has been estimated that TGD people make up $0.5 \%-2.7 \%$ of the population in the USA depending on the breadth of the definition used $^{23}$ and $0.6 \%$ in the UK. ${ }^{4}$ These are likely to be underestimates as data on prevalence are mostly derived from clinic attendance figures such as in the UK Gender Identity Services (GIS), a specialist health service for TGD people. GIS provides access to psychotherapy and interventions to aid transition including hormone replacement therapy and surgical interventions. Access to GIS is made through a referral by a family practitioner or other health specialist. ${ }^{5}$ However, not all TGD persons will want or are able to seek access to such services. ${ }^{6}$ Nevertheless, referrals to GIS have increased in recent years, possibly because of increasing awareness through depiction in the media and greater access to information on transitioning. ${ }^{6}$ Previous reviews have explored themes relating primarily to mental health and prevalence of TGD people in the population. ${ }^{27}$ These reviews show an increase in prevalence, characterised by referrals made to GIS, and increases in depression and anxiety disorders compared with the general population. 
Conversion therapies and access barriers to transition-related healthcare

Conversion therapy for TGD people is a general term to describe treatments that aim to suppress or divert affirmed gender; in short to make the person cisgender, that is, no longer TGD. In 2015, a Memorandum of Understanding against the use of conversion therapies in lesbian, gay and bisexual (LGB) people was agreed by health professional bodies in the UK, such as the Council for Psychotherapy, the Royal College of Psychiatrists and NHS England. ${ }^{89}$ In 2017, a revised Memorandum was published which extended advice to cover TGD people outside of the UK organisations internationally, such as the Australian Psychological Society, and the American Psychological Association have released position statements on the use of conversion therapies with TGD people. ${ }^{10}$ Although there has been considerable research into conversion therapies in LGB people, ${ }^{11-14}$ much less is known about what such therapies in the UK and elsewhere may entail for TGD people, ${ }^{15}$ and how widespread such practices might be.

There have been increasing reports in the media of poor transition-related healthcare in TGD people. This includes conversion therapies in young TGD people and options given to TGD adults for conversion interventions. ${ }^{16}$ One extreme example comes from the USA, where the then president, Barack Obama, spoke about Leelah Alcorn's case, a young transgender girl who committed suicide in 2015. ${ }^{1617}$ Her suicide was attributed to her being taken to Christian therapists who told her that her affirmed gender was wrong. This case was brought to international attention and featured in national newspapers and journals, for example, Time magazine headlined the case as 'Leelah Alcorn's Suicide: Conversion Therapy Is Child Abuse'. Other examples are also evident in media accounts, particularly with regards to TGD youth and access to puberty-delaying medications. Puberty-delaying medications slow the process of natal sex puberty and thus allow TGD youth more time to explore their gender before commencing cross-sex hormone replacement therapy. ${ }^{18}$ Accessing these medications has been shrouded in controversy, with media accounts denying the benefits of allowing access and other accounts expressing the necessity of allowing access. ${ }^{18} 19$ These reports are dominated by a discourse about persistence or desistance of gender dysphoria into adulthood ${ }^{20}$ and little consideration has been made of the concept that denying access may constitute a form of conversion therapy, obliging those who meet the criteria for a gender dysphoria diagnosis to continue physically in their natal sex.

There has been long-standing controversy about the use of words such as 'desistance' and 'persistence'. This review acknowledges that so-called desistance has been poorly understood because of inadequate study design, such as labelling a child as desisting when they were no longer contactable, and low participant numbers. ${ }^{21}$ The statistic often quoted from desistance literature suggests that about $85 \%$ of gender-diverse youth, including children with diagnosable gender dysphoria, will not go on to being gender dysphoric adolescents/ adults. $^{22} 23$ However, a critical commentary of this has been published, ${ }^{24}$ in which four commonly cited papers were reviewed for methodological, theoretical, ethical and interpretive concerns. ${ }^{21} 232526$ The findings suggest 12 concerns with desistance. The first group was methodological, which included potential misclassification of child research participants as dysphoric, lack of acknowledgement of social context, age of participants at follow-up, potential misclassification of adolescents and adults lost to follow-up considered as no longer dysphoric. The second was theoretical: assumptions inherent in desistance terminology (positioning gender development as 'normal' or 'deviant'), binary gender framework (omitting the diversity of gender expression and identities) and a presumption of gender stability as a positive outcome. The third group were ethical: intensive treatment and testing of child participants, questionable goals of treatment (prevention of TGD adolescence and adults) and lack of consideration of children's autonomy. The final group was interpretive: an assumption that unknown future adult needs should supersede known childhood needs and an underestimation of harm when attempting to delay or defer transition. The last interpretive concern is of direct interest to this review and suggests that withholding treatment for TGD youth is more harmful than beneficial.

In this paper, we present a review of the published research literature on the extent of practice of conversion therapies and barriers to access transition-related healthcare, and their mental health consequences. Our objectives were as follows:

1. Describe the frequency, nature and structure of conversion practices.

2. Document the difficulties in accessing transition-related healthcare.

3. Evaluate the mental health consequences of such practices and access barriers.

\section{METHODS}

This systematic review is registered with PROSPERO database (CRD42017062149).

\section{Definitions and eligibility criteria}

We defined conversion as therapies that seek to change or suppress a person's sexual orientation or gender. This definition was adapted from conversion efforts in LGB people. ${ }^{27}$ We defined access barriers as attempts made to prolong or stop appropriate transition-related medication or therapy from occurring by healthcare professionals/TGD healthcare gatekeepers. We included studies focusing on TGD people that (1) document the use of conversion therapies or access barriers to transition-related healthcare; and/or (2) describe how such therapeutic practices and access barriers have been applied and/or (3) evaluate the mental health impacts 
of such therapies and barriers to access. TGD people of all ages, both within the UK and worldwide, were eligible populations for inclusion. Included was primary research written in English in the form of case studies, cross-sectional or cohort studies, case-control studies, qualitative studies, randomised clinical trials or other forms of epidemiological or experimental investigation. With regards to barriers, our focus was on intentional/purposeful barriers set up by healthcare professionals that aim to reduce or halt access to transition-related interventions, that is, refusal to refer to specialist services for puberty-delaying medication/cross-sex hormones, refusal to offer transition-related healthcare. This therefore excludes discrimination in a general healthcare context, or barriers to help-seeking, as these do not constitute as attempts to force natal sex development. We accept that others may take our definition as too narrow.

\section{Outcomes}

Our main outcomes were evidence of the nature and occurrence of conversion therapies and access barriers to transition-related healthcare, as well as their mental health outcomes, such as depression, anxiety, suicidal ideation or attempts.

\section{Search strategy}

Embase, MEDLINE, PsychoINFO, PsychARTICLES and Web of Science were searched from 1 January 1990 to 30 June 2017. The year 1990 was chosen as we assumed earlier research might be at a higher risk of conflating sexual orientation and gender identity. ${ }^{28}$ Search terms selected were those used in previous reviews of LGB conversion therapy $^{27}$ and earlier TGD reviews ${ }^{27}$ and examples were taken from MEDLINE below. All terms were used in each database in the same sequence:

\section{MEDLINE (OVID)}

1. (conversion* or reparative* or reorientation* or repair* or barring* or prevent* or affirm* therapy or affirm* or non-affirm* or non-affirm* therapy or access or maltreatment or refer* or rejection or block*). mp. [mp=title, abstract, original title, name of substance word, subject heading word, keyword heading word, protocol supplementary concept word, rare disease supplementary concept word, unique identifier, synonyms]

2. (transgender or transsexual or gender identity disorder or gender dysphoria or GID or cross-dressing or intersex or MTF or FTM or gender queer or gender non-conforming).mp. [mp=title, abstract, original title, name of substance word, subject heading word, keyword heading word, protocol supplementary concept word, rare disease supplementary concept word, unique identifier, synonyms]

3. 1 AND 2.

Citations were screened by one author (TW), while a sample of 200 citations identified randomly were reviewed by the other authors to check agreement. Should disagreements have been identified, they would have been settled by discussion and further samples checked until satisfactory agreement had been achieved.

\section{Data extraction}

Key study data were extracted according to study aim, design, participants, intervention type, outcome measures and main findings. Extraction was undertaken by TW and checked by BC.

\section{Data presentation and synthesis}

Data from the included studies were grouped according to each of our review objectives. We sought to present quantitative data in standardised formats, such as mean score differences, together with statistical significance and confidence levels. A meta-analysis was planned, where enough experimental studies were to be found with sufficient homogeneity across them. In the event, however, only descriptive accounts were possible. For any qualitative evidence, we sought to present narratives of conversion approaches in relation to our research objectives. This approach was chosen due to the narrative nature of the included studies, all of which follow a timed structure. ${ }^{29}$ Barriers to access were examined using a thematic analytical approach.

\section{Quality assessment of studies}

The instruments we used to rate quality of the studies were dependent on the design of each study. Assessment of study quality for case studies identified was undertaken using a Joanna Briggs Institute (JBI) Critical Appraisal Tool. ${ }^{30}$ The JBI critical appraisal tool assesses methodological quality using the following eight items: the participant's history, demographics, assessment/diagnostic methods, preclinical condition, postclinical condition, description of intervention(s), serious adverse events and key take home messages. Assessment of study quality, for both qualitative, and cohort studies identified, was undertaken using tools for the Critical Appraisal Skills Programme (CASP). ${ }^{31} 32$ The CASP was applied to the barrier to healthcare papers. The CASP Cohort assesses quality on 11 questions using a yes/no/unsure/not applicable score. The CASP Qualitative assesses quality on 10 questions using a yes/no/unsure/not applicable score. These answers were then summed to provide an overall picture of quality. If we had identified any randomised trials, we would have considered using Cochrane recommended assessment tools. Should we have identified other studies using other designs, we would have selected recommended instruments by consulting method experts. Two authors assessed the quality of each study, and should there have been any disagreements in their assessments, discussion with the third author would have been held to reach a consensus.

\section{Funding}

This review did not receive external funding. 


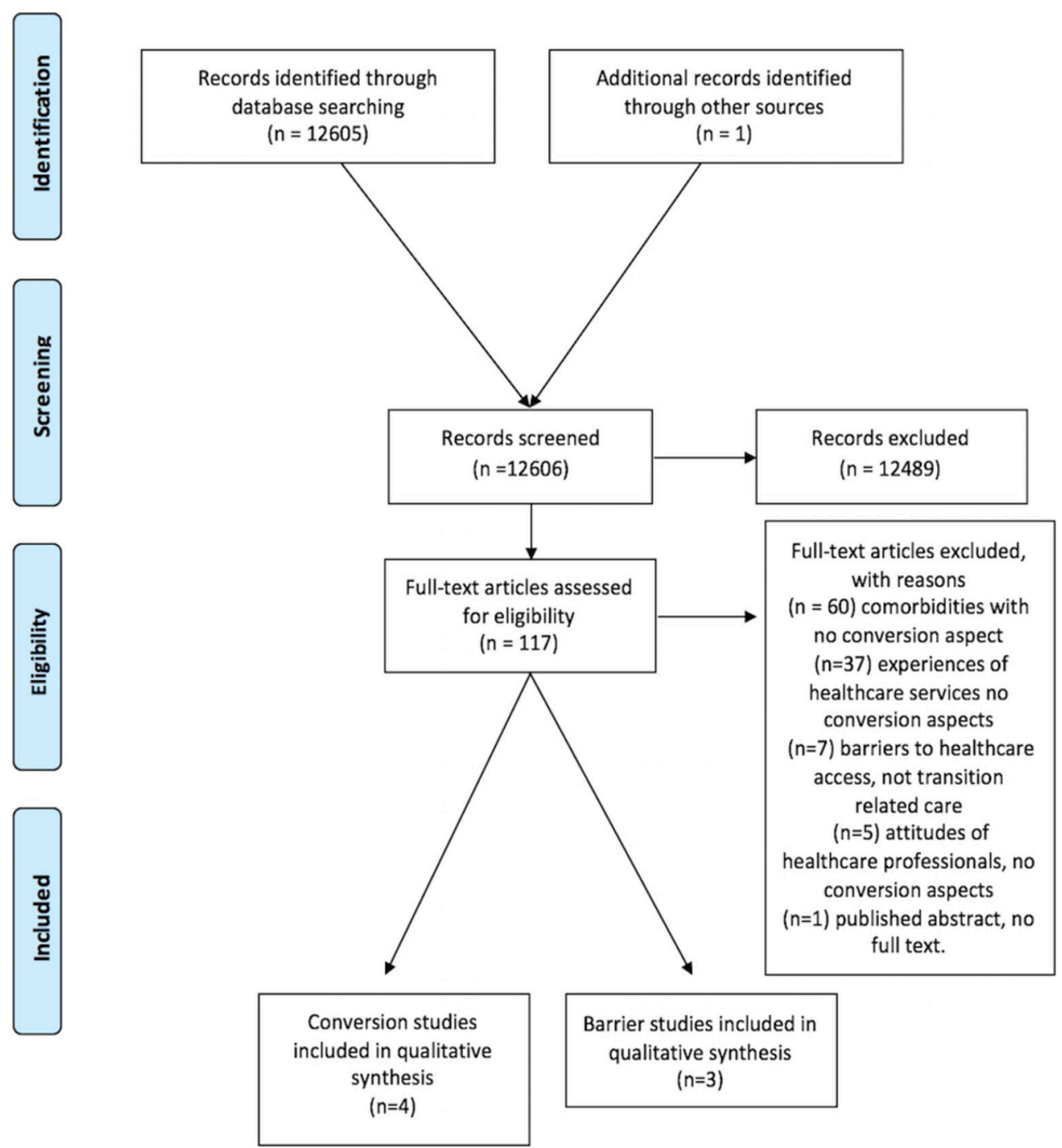

Figure 1 Flow chart of the studies retrieved using the search terms and strategy.

\section{Patient and public involvement}

Patients and the public were not involved in the conception or running of this review.

\section{RESULTS}

\section{Summary of included studies}

The search strategy yielded 12606 citations for screening. After the initial screening of citations, 117 were considered relevant and full texts retrieved for review. In total, 110 articles did not meet the eligibility criteria (see figure 1 ). Seven studies fulfilled inclusion criteria. Four were case studies of conversion therapy ${ }^{33-36}$ and three concerned barriers to healthcare for gender transition. ${ }^{37-39}$

\section{Conversion therapies}

Three of the four studies on conversion therapies originated from the USA and Canada, and one from the U.K. They were published between 1997 and 2012. The therapies used in conversion were psychoanalysis, self-exposure therapy and open-ended play psychotherapy. The two psychoanalytic case studies, one self-exposure therapy study and one open-ended play psychotherapy presented longitudinal data in a qualitative research design. Key characteristics of these studies are detailed in tables 1 and 2.

Three studies were overall of poor methodological quality and one was of good methodological quality (see table 3). Of the poor designs, none used appropriate diagnostic tests or assessment methods of gender either before or after the intervention. The type of intervention was stated in broad terms (ie, psychoanalysis or self-exposure therapy), but the procedures were not described in two of the studies. ${ }^{33} 34$ Two did not clearly describe the details on identification as transgender. ${ }^{33} 34$ Of the good design, preclinical and postclinical condition was given and good detail given on the assessments and treatments. All gave a case timeline, some demographics and a conclusion.

Case study 1: Andy

Zienst $^{33}$ describes a 7 -year-old assigned male at birth who was brought to the psychodynamic therapist by the 
Table 1 Descriptive display of psychotherapeutic conversion therapies

\begin{tabular}{lll}
\hline $\begin{array}{l}\text { Study title, author } \\
\text { and year }\end{array}$ & $\begin{array}{l}\text { Participant } \\
\text { information }\end{array}$ & Aims \\
\hline $\begin{array}{l}\text { Andy: A boy who } \\
\text { thought he needed to } \\
\text { be a girl, Zienst, A.B } \\
(2003)^{33}\end{array}$ & $\begin{array}{l}\text { Seven-year-old male } \\
\text { assigned at birth. }\end{array}$ & $\begin{array}{l}\text { To demonstrate the } \\
\text { multidetermined } \\
\text { functions of feminine } \\
\text { identifications and } \\
\text { strivings in a boy } \\
\text { with a diagnosable }\end{array}$ \\
& & $\begin{array}{l}\text { gender identity } \\
\text { disorder. }\end{array}$ \\
$\begin{array}{l}\text { Gender identity } \\
\text { disorder in a girl: } \\
\text { insights from } \\
\begin{array}{l}\text { adoption, Gilmore, K } \\
(1995)^{34}\end{array}\end{array}$ & $\begin{array}{l}\text { Female assigned } \\
\text { at birth initially } \\
\text { presented at age six } \\
\text { to analyst. }\end{array}$ & $\begin{array}{l}\text { To offer insights } \\
\text { into gender } \\
\text { identity disorder } \\
\text { in girls, through } \\
\text { the examination of } \\
\text { aetiological factors. }\end{array}$ \\
& &
\end{tabular}

\begin{tabular}{|c|c|c|c|c|c|c|}
\hline $\begin{array}{l}\text { Four Year Remission } \\
\text { of transsexualism } \\
\text { after comorbid } \\
\text { obsessive compulsive } \\
\text { disorder improved } \\
\text { with self-exposure } \\
\text { therapy, Marks, I.M, } \\
\text { and Mataix-Cols, D. } \\
(1997)^{35}\end{array}$ & $\begin{array}{l}\text { Male assigned at } \\
\text { birth, identified } \\
\text { as female since } \\
15 . \text { Presented to } \\
\text { therapist at } 42 \text { with } \\
\text { OCD, had attended } \\
\text { GIS since } 32 / 33 \text {. }\end{array}$ & None stated. & $\begin{array}{l}\text { Self-exposure } \\
\text { therapy. }\end{array}$ & None stated. & $\begin{array}{l}\text { Through therapy, } \\
63 \text { days later, self- } \\
\text { rated OCD had } \\
\text { improved by } 90 \%, \\
\text { transsexuality and } \\
\text { homosexuality } \\
\text { also remitted } \\
\text { as researchers } \\
\text { evidenced } \\
\text { 'masturbation } \\
\text { three times a week } \\
\text { to heterosexual } \\
\text { images'. } \\
\text { By } 17 \text { months' post } \\
\text { discharge feelings of } \\
\text { anxiety, depression } \\
\text { and anxiety were } \\
98 \% \text { better and } \\
\text { identity still male. }\end{array}$ & $\begin{array}{l}\text { At } 6 \text { years follow- } \\
\text { up participant's } \\
\text { identification as } \\
\text { transgender had } \\
\text { 'recurred' } 2 \text { years } \\
\text { prior. Returned to } \\
\text { oestrogen } 11 \text { months } \\
\text { prior to follow-up } \\
\text { and was awaiting } \\
\text { gender affirmation } \\
\text { surgery. }\end{array}$ \\
\hline $\begin{array}{l}\text { A developmental, } \\
\text { biopsychosocial } \\
\text { model for the } \\
\text { treatment of children } \\
\text { with gender identity } \\
\text { disorder. Zucker et al } \\
(2012)^{36}\end{array}$ & $\begin{array}{l}7 \text { children aged } \\
\text { under } 10 \text { years } \\
\text { used as clinical } \\
\text { case examples of } \\
\text { treatments used by } \\
\text { Toronto's gender } \\
\text { identity clinic to } \\
\text { resolve gender } \\
\text { dysphoria in gender } \\
\text { diverse youth. }\end{array}$ & $\begin{array}{l}\text { To give summary of } \\
\text { treatment protocols } \\
\text { by the Centre for } \\
\text { Addiction and Mental } \\
\text { Health in Toronto, } \\
\text { Canada. } \\
\text { To give descriptions } \\
\text { of assessment } \\
\text { and multifactorial } \\
\text { formulation in } \\
\text { treatment of gender } \\
\text { dysphoric youth. }\end{array}$ & $\begin{array}{l}\text { Various treatments; } \\
\text { open-ended play } \\
\text { psychotherapy. } \\
\text { Parent counselling, } \\
\text { parent-guided } \\
\text { interventions } \\
\text { in naturalistic } \\
\text { environments, } \\
\text { psychotropic } \\
\text { medication for } \\
\text { co-occurring } \\
\text { psychopathology. }\end{array}$ & $\begin{array}{l}\text { Based on parent's } \\
\text { wishes. If the parent } \\
\text { wishes for the child } \\
\text { to be comfortable } \\
\text { in their natal sex, } \\
\text { the therapeutic } \\
\text { intervention is } \\
\text { centred on this goal. } \\
\text { Prevention of } \\
\text { transsexualism is } \\
\text { a treatment goal } \\
\text { for those who } \\
\text { are believed to } \\
\text { 'desist' from gender } \\
\text { dysphoria into } \\
\text { adulthood. }\end{array}$ & $\begin{array}{l}\text { It is of Zucker et al's } \\
\text { belief that gender } \\
\text { identity disorder } \\
\text { had remitted in the } \\
\text { majority of their } \\
\text { clients, through } \\
\text { the use of their } \\
\text { interventions. }\end{array}$ & $\begin{array}{l}\text { Mention is made } \\
\text { of those who did } \\
\text { go on to transition; } \\
\text { however, emphasis } \\
\text { is placed on other } \\
\text { mental health } \\
\text { problems and } \\
\text { addictions. } \\
\text { 'Another natal female } \\
\text { was originally seen } \\
\text { for assessment at } \\
\text { the age of } 12 \text { years } \\
\text { and followed } \\
\text { up at the age of } \\
26 \text {... However, he } \\
\text { struggled with severe } \\
\text { alcohol abuse, } \\
\text { abused recreational } \\
\text { drugs, had been } \\
\text { frequently arrested } \\
\text { for getting into fights } \\
\text { while intoxicated, } \\
\text { and was occasionally } \\
\text { suicidal.' }\end{array}$ \\
\hline
\end{tabular}

OCD, obsessive compulsive disorder; GIS, Gender Identify Service.

mother. The reason for this was that a friend's mother instructed her son not to play with Andy due to Andy's 'coquettishly pretending he was a girl'. Zienst highlights Andy's physical appearance, reporting that he had a 'short stature' and was 'physically less developed than the other boys'. Zienst uses only masculine pronouns despite Andy's initial desire to transition, evidenced by the following quotes: 'he freely talked about his wishes 
Table 2 Descriptive display of barrier papers

\begin{tabular}{|c|c|c|c|c|c|}
\hline $\begin{array}{l}\text { Study title, author } \\
\text { and year }\end{array}$ & $\begin{array}{l}\text { Study design/ } \\
\text { participant } \\
\text { information }\end{array}$ & Aims & Outcome measures & Main findings & Follow-up \\
\hline $\begin{array}{l}\text { Youth and caregiver } \\
\text { perspectives on } \\
\text { barriers to gender- } \\
\text { affirming health care } \\
\text { for transgender youth. } \\
\text { Gridley et al }(2016)^{37}\end{array}$ & $\begin{array}{l}\text { Qualitative: interviews, } \\
\text { focus groups and online } \\
\text { surveys. } \\
15 \text { transgender youth } \\
\text { aged between } 14 \text { and } \\
22 \text {, and } 50 \text { parents. } \\
\text { Majority of participants } \\
\text { were white ( } 67 \% \text { and } \\
78 \% \text {, respectively) } \\
80 \% \text { of trans youth } \\
\text { were too old/ineligible } \\
\text { for puberty blockers. }\end{array}$ & $\begin{array}{l}\text { To understand barriers } \\
\text { for transgender youth } \\
\text { and caregivers in } \\
\text { accessing healthcare } \\
\text { services. }\end{array}$ & None stated. & $\begin{array}{l}\text { Insurance refusals, delays in } \\
\text { hormone blockers and cross } \\
\text { sex hormone prescription, } \\
\text { inconsistent use of pronoun/ } \\
\text { name, few accessible gender } \\
\text { affirming practitioners, lack } \\
\text { of consistent protocols, } \\
\text { uncoordinated care and } \\
\text { gatekeeping were all factors } \\
\text { consistent with experiences of } \\
\text { barriers in healthcare services. }\end{array}$ & None stated \\
\hline $\begin{array}{l}\text { Health Care providers } \\
\text { comfort with and } \\
\text { barriers to care of } \\
\text { transgender youth. } \\
\text { Vance et al }(2015)^{38}\end{array}$ & $\begin{array}{l}\text { Survey. } \\
475 \text { members from the } \\
\text { Society for Adolescent } \\
\text { Health and Medicine } \\
\text { and the Pediatric } \\
\text { Endocrine Society were } \\
\text { recruited. }\end{array}$ & $\begin{array}{l}\text { To explore provider } \\
\text { side barriers to giving } \\
\text { care to TGD youth. }\end{array}$ & $\begin{array}{l}\text { 36-item survey } \\
\text { comprising questions } \\
\text { on demographic } \\
\text { information, practice } \\
\text { characteristics, } \\
\text { clinical exposure to } \\
\text { transgender youth } \\
\text { aged 8-21 years, } \\
\text { familiarity with and } \\
\text { adherence to existing } \\
\text { clinical practice } \\
\text { guidelines, and } \\
\text { perceived barriers } \\
\text { to and comfort and } \\
\text { confidence with } \\
\text { providing transgender- } \\
\text { related care. }\end{array}$ & $\begin{array}{l}62 \% \text { reported feeling } \\
\text { comfortable providing care } \\
\text { to TGD people. } 6.4 \% \text { of } \\
\text { healthcare providers objected } \\
\text { to treating TGD people } \\
\text { medically based on religious } \\
\text { and cultural beliefs. } \\
14.3 \% \text { reported } \\
\text { discouragement from } \\
\text { colleagues. } \\
38 \% \text { have prescribed } \\
\text { transgender-related } \\
\text { medications (puberty blockers/ } \\
\text { cross-sex hormones). } \\
\text { Physician-related barriers } \\
\text { include lack of training, little } \\
\text { exposure to TGD patients, } \\
\text { insurance reimbursement } \\
\text { issues and lack of mental } \\
\text { health professionals. Despite } \\
\text { high willingness to offer care. }\end{array}$ & NA \\
\hline
\end{tabular}

NA, not available; TGD, transgender and gender diverse.

to be a girl' and how the work 'might take these interests from him'. Andy's identity was described as suppressed through psychoanalysis by Zienst by placing emphasis on the interactions of Andy's parents, as well as Andy's development and environment. This resulted in 'He ... told me that now he really did want to be a boy because a boy didn't just have to do boy things but could do some girl things'. Zienst provided a quasi-follow-up roughly 6 years after the course of psychoanalysis, in which Andy phoned Zienst during the freshman year at college with worries about being called gay.
Case study 2: Samantha

In Gilmore, ${ }^{34}$ the researcher analyst concludes that an adoption that involved living with a new family had predisposed the patient to develop a gender identity disorder. The young person, Samantha, was removed from the foster mother between the age of 6 months and 1 year due to an adoption taking place. Samantha was presented to the analyst at the age of six, after several years of 'preference for maleness'. Gender identity disorder was explored through role play and storytelling in which Samantha maintained a male role and openly 
Table 3 Summary of the methodological quality of the conversion therapy studies

\begin{tabular}{|c|c|c|c|c|}
\hline & Zienst $^{33}$ & Gilmour $^{34}$ & $\begin{array}{l}\text { Marks and Mataix- } \\
\text { Cols }^{35}\end{array}$ & Zucker et al ${ }^{36}$ \\
\hline $\begin{array}{l}\text { 1. Were the patient's } \\
\text { demographics clearly } \\
\text { described? }\end{array}$ & Yes & Yes & Yes & Yes \\
\hline $\begin{array}{l}\text { 2. Was the patient's history } \\
\text { clearly described and } \\
\text { presented as a timeline? }\end{array}$ & Yes & Yes & Yes & Yes \\
\hline $\begin{array}{l}\text { 4. Were diagnostic tests } \\
\text { or assessment methods } \\
\text { and the results clearly } \\
\text { described? }\end{array}$ & Unclear & NA & NA & Yes \\
\hline $\begin{array}{l}\text { 6. Was the postintervention } \\
\text { clinical condition clearly } \\
\text { described? }\end{array}$ & NA & NA & Yes & Yes \\
\hline $\begin{array}{l}\text { 7. Were adverse events } \\
\text { (harms) or unanticipated } \\
\text { events identified and } \\
\text { described? }\end{array}$ & Unclear & Unclear & Yes & Yes \\
\hline $\begin{array}{l}\text { 8. Does the case report } \\
\text { provide takeaway lessons? }\end{array}$ & Yes & Yes & Yes & Yes \\
\hline
\end{tabular}

NA, not available.

expressed the wish to be a boy. The researcher claimed that pre-oedipal disruption of being separated from the foster mother had led to a separation anxiety in which a male identity was formed as a protection against psychic pain. Gilmore claimed that the persistent wish to be the other sex, including acquiring parts of the opposite sex, was an attempt to resolve these internal conflicts. When Samantha was 11, Gilmore states: 'She then shifted the discussion to girls' potential to be anything, including male, by means of a sex change. Here again she defensively avoided feminine success, wishing for a penis to complete her body.' A further 2 years of treatment took place, which focused on transference themes arising from struggles with the mother figure. It is within these 2 years that a shift occurred towards a cisgender identity; however, the researcher does not make it clear as to what was done to facilitate this change. Gilmore claimed that the pre-oedipal stage is a time when young girls come to understand gender differences, and that gender disturbance which first arises in childhood is the result of the psychological removal of the mother figure.

Case study 3: anonymous

In a case study by Marks and Mataix-Cols, ${ }^{35}$ the participant's history is more detailed. The participant's natal sex was male, but identification was as female from the age of 15 . The individual was 42 years of age at the start of the study, but had been cross-dressing in feminine clothes from the age of 7 . She had attended Gender Identity Clinics between the ages of 32 and 37 and was taking the hormone oestrogen in a bid to affirm her desired gender. She had also taken an overdose at the age of 16 intending to end her life after a 'family row over his transsexualism and homosexuality'. It is worth noting here that the individual was referred specifically for clinical treatment of her obsessive compulsive disorder (OCD) and had refused treatment for 'transsexualism'. The treatment itself was referred to as self-exposure therapy and was described as 'self-exposure to ritual inducing situations with self-imposed prevention of rituals'. Although it was reported as a highly effective treatment for depression, anxiety and OCD, the authors also claimed to have shifted the patient's gender identity towards cisgender. However, at 6 years follow-up, it was reported that the participant had returned to the clinic dressed as a woman, having started 2 years earlier, and was awaiting gender affirmation surgery, having taken oestrogens for 11 months. 


\section{Case examples 4}

In a series of case examples presented from the Centre of Addiction and Mental Health in Toronto, Canada, ${ }^{36}$ seven children under the age of 10 were described in terms of demographic characteristics, assessment, formulation and treatment plan. The paper describes an assessment period of 3-4 clinic visits by the gender-diverse youth and their primary caregiver. A formulation of the case then shaped the treatment goals. This was often led by the primary caregiver's desires for the child,

If the parents are clear in their desire to have their child feel more comfortable in their own skin, that is, they would like to reduce their child's desire to be of the other gender, the therapeutic approach is organized around this goal.

This treatment was often conducted using openended play psychotherapy, where the clinician explores gender through dolls and other toys in order to allow a gender-diverse child to talk through their gender. Primary caregivers are also involved in psychotherapy, exploring how their own behaviour may cause and maintain gender dysphoria in their child. Primary caregivers would be encouraged to put limitations on cross-gender behaviour. Zucker et al argued that gender dysphoria is reparable, while sexual orientation is not. They argued that despite a remission in gender dysphoria in a child repression of eventual sexual orientation was not a treatment goal offered by the service. The main argument proposed by the authors was that of poor psychosocial functioning as a TGD adult in those who may have 'persisted'. The argument stemmed from a wish for the gender-diverse youth to have a well-functioning adulthood and to be comfortable in their own skin. Furthermore, the authors estimate their own persistence rate of gender dysphoria into adolescence at $12 \%-14 \%$.

\section{Difficulties in accessing TGD-related healthcare}

Three studies on barriers to transition-related healthcare were identified. ${ }^{37-39}$ One was on American TGD youth $(n=15)$ and their parents $(n=60)^{37}$ which used a qualitative research design to explore their perspectives on access barriers. The other two explored health professionals' knowledge and practice in providing transition-related healthcare. ${ }^{3839}$ One of these studies gained, via an online survey, 475 responses from a multidisciplinary group of American professionals who were members of the Society for Adolescent Health and Medicine. Of these, $66.5 \%$ had provided care to transgender youth. The other captured the perspectives of 15 American physicians via semistructured interviews. Using qualitative analysis of the transcripts, the authors explored thematically barriers faced by physicians when caring for TGD patients. We found these studies overall had good methodological quality (see table 4). All had clear research aims and described data analysis.

Predominant themes in the paper on TGD people, and their parents, with regards to access barriers to transition related healthcare, ${ }^{37}$ indicated difficulties in accessing puberty-delaying medications. This was attributed to a lack of consistently applied protocols. Further reports described patients from whom puberty-delaying treatments had been withheld, despite their meeting the criteria for gender dysphoria. Furthermore, larger-scale factors played a role in difficulties accessing transition-related healthcare, such as insurance refusals and a lack of knowledgeable providers to turn to for beginning a phys$\mathrm{ical} /$ medical transition. It was also reported that healthcare providers would use incorrect pronouns and names when referring to their TGD patients.

The other studies exploring healthcare providers' views on TGD-related healthcare provision ${ }^{38} 39$ reported that despite a willingness to offer care several difficulties were raised. These were uncertainty about exactly what to $\mathrm{do}^{32}$; religious conflicts that sometimes posed a barrier to providing care $(6.4 \%$ of 475 healthcare providers refused to treat TGD people based on their religious beliefs $)^{31}$ and discouragement from colleagues. ${ }^{31} 32$ Finally, a dominant theme was the absence of access to mental health professionals, who could aid in the transition process by providing psychological support. Healthcare providers described an inability to identify mental health professionals who specialised in gender dysphoria. In both studies, it was apparent that there is a need for further training and knowledge in transition-related healthcare.

\section{DISCUSSION}

To our knowledge, this is the first systematic review of conversion therapies and access barriers to transition-related healthcare in TGD people. It aimed to review the nature and extent of conversion therapies in TGD people, access barriers to transition-related healthcare and the mental health consequences of both.

Seven published studies were eligible. Four were on specific conversion attempts, in which the treatments were poorly described. Although psychoanalysis, exposure therapy and play psychotherapy were used to bring about this change, two of the included studies could not justify the nature of the therapies used, and none appropriately assessed mental health outcomes. The three other studies explored access to appropriate transition-related treatments. It was clear that difficulties existed not only in terms of access to treatments to delay or block puberty in TGD youth, but also regarding physicians' personal preparedness to offer treatment or their knowledge about directing patients to appropriate specialist care. There was no assessment of the mental health consequences of such barriers in the studies.

\section{Interpretation}

1. Describe the frequency, nature and structure of conversion practices.

We found limited evidence in the research literature of the use of conversion therapies that aimed solely at suppressing or modifying what was considered by the 


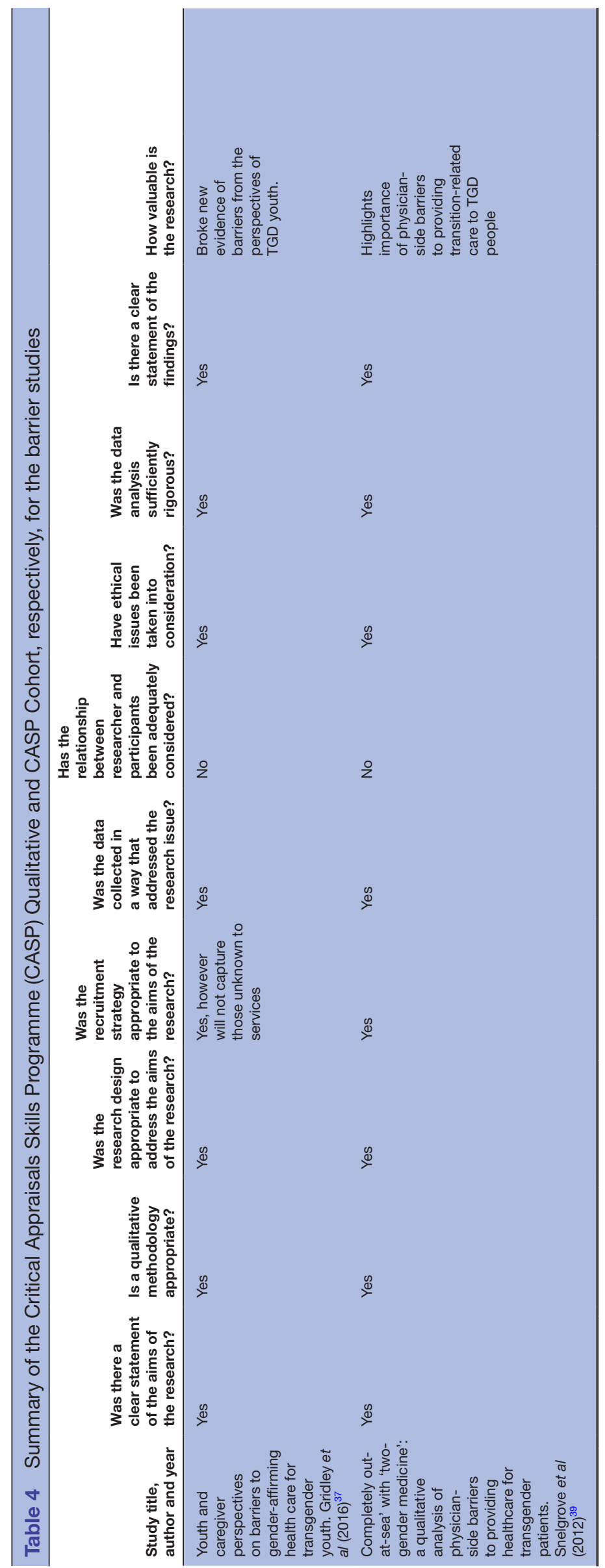

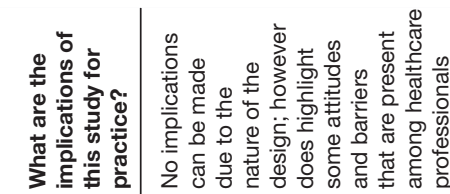

$\pm \frac{2}{6}$

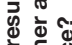

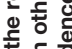

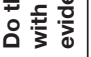

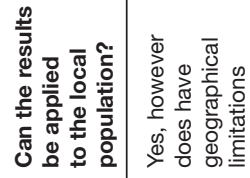

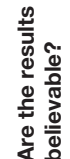

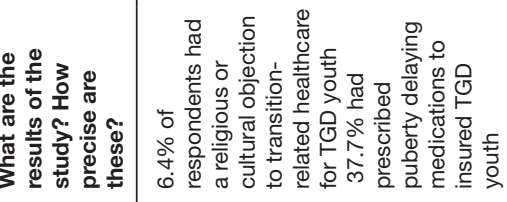

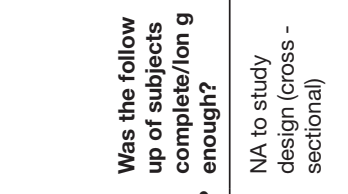

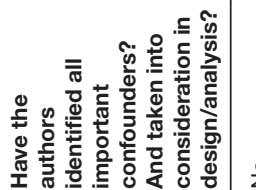
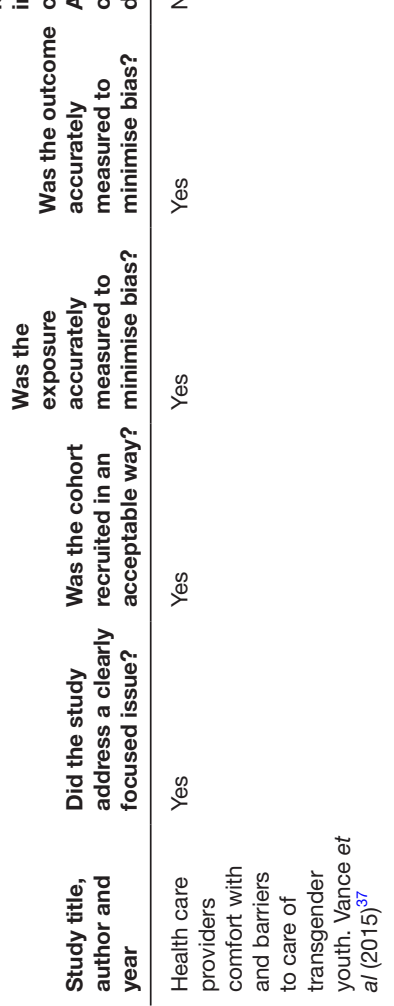

. 
therapist as abnormal gender identity. The four case study papers identified were published between 1997 and 2012. Had our search extended prior to 1990, we would have identified more evidence on the practice. However, there was a risk historically that the conflation of gender diverse with gay and lesbian people would have made identification of treatments difficult. ${ }^{28}$ We are aware of at least two papers published before 1990 that describe explicit attempts to change the gender of several TGD people. ${ }^{40} 41$ These studies both used electric aversion therapy with results indicating that no change had occurred. Both articles were published in the late 1960s and early 1970s, and both indicate that conversion approaches in TGD people were ineffective.

The treatment approaches took the view that TGD people arose from impaired development and inappropriate caregiver role models. They echo previous claims for the pathological basis of same-sex sexual orientation. They were also similar to the practice of LGB conversion therapy from the 1960s to the 1980s in which psychodynamic and behaviour therapies were used. ${ }^{42}$ Here, however, there was no attempt in three of the included studies to explain how the therapy was carried out. For example, although self-affirmation as transsexual preceded the onset of OCD in Marks's and Mataix-Cols' case, the treatment goal was not only to alleviate the symptoms of OCD, but also to alleviate 'symptoms' of transsexualism. Thus, perhaps it is not surprising that the authors' final remarks are somewhat muddled: 'This case and others show that gender identity and paraphilias can remit for years after comorbid OCD and other disorders improve with various treatments.' The paper by Zucker, however, did describe how their open-ended play psychotherapy was conducted, and their goal was also stated broadly as prevention of transsexualism. The authors do not suggest reorienting future sexual orientation; however, have mirrored previous studies in LGB conversion, particularly with regards to behavioural modification. ${ }^{12}$

Furthermore, with regards to Zucker et als paper, we are aware of the controversy about his practices, with many families and TGD people regarding the work as reparative in nature. The authors were not adopting a 'watch and wait' policy but were attempting to reduce cross-gender identification. The paper also heavily relies on 'desistance' statistics. As mentioned previously, a recent critical review of desistance literature covers methodological, theoretical, ethical and interpretive concern of these follow-up studies. ${ }^{24}$ It highlights the potential of misclassification of children having gender dysphoria, the problem of those lost to follow-up being classified as a 'desistor' and assumptions about grounding in a binary gender framework. The commentary also takes a stance with regards to regret by suggesting that children may perhaps transition again in the future, and that this event would be traumatic. While regret is conceivable, it is rare, and therefore does not justify the argument that gender-diverse youth should be restricted in their gender expression. ${ }^{24}$
2. Document difficulties in accessing transition-related healthcare.

In our search, we identified 11 studies of barriers to general healthcare encountered by TGD people. ${ }^{37-39} 43-49$ However, only three of these studies were suitable for inclusion in the review using a strict viewpoint of barriers accessing transition-related healthcare.

These studies were all published in the past 5 years and and may explain the common perception of TGD people that access to what they regard as appropriate healthcare is restricted. They suggest evidence of restricting/denial of access to transition related healthcare, particularly in the case of TGD youth. They also highlight the issue of cis-heteronormativity, which assumes TGD people are not authentically the gender with which they identify. This in turn means that TGD youth and adults risk encounters with healthcare providers who have assumptions about gender and sex that are incongruent with their own views. The predominant themes in these studies were delayed/postponed healthcare seeking due to the barriers encountered. Within TGD youth, the emphasis was on an inability to access puberty delaying medications and hormone replacement therapy. Furthermore, reasons for objections to the provision of transition-related healthcare arose from lack of knowledge, as well as the religious/spiritual beliefs, of providers. Although research into the psychosocial functioning of TGD youth who take puberty-delaying medications shows improvements compared with same-age peers, and a resolution of dysphoria related to gender, ${ }^{50}$ physicians may have uncertainties about starting puberty-delaying treatments in very young TGD people.

It is worth noting that gender identity clinics were founded on rigid concepts of the 'true transsexual', to mean a heterosexual person who wishes to transition to the opposite sex. Historically, there was no place for people with more subtle combinations of gender identification and sexual orientation, who were often seen as unsuitable for transition. ${ }^{51}$

3. Evaluate the mental health consequences of such practices and access barriers.

The mental health consequences of conversion therapies were poorly described and no reports from the patients were included. The treatments did not appear to lead to any obvious change in their status as TGD people. Furthermore, the methodological rigour of the included studies was mixed, with three being poor and four being good. Most studies did not include participants' own accounts and instead relied on the interpretations of the therapists. This is particularly alarming as the outcomes of these conversion therapies are based on the assumptions made by the therapist as opposed to validated measures, such as The Gender Preoccupation and Stability Questionnaire (GPRSQ). ${ }^{52}$ The GRPSQ is a tool used to assess gender dysphoria outcomes regardless of intervention type, that is, surgical, medical or psychological. The lack of validated assessments over the follow-up in these studies also suggests that little 
consideration was made of the benefits or harms of such interventions.

In Zucker's paper, there is a clear focus on the future adult's needs. These future adult needs emphasised the risk of social ostracism, and therefore attempting to alter gender within children and young people was assumed to reduce this risk. No longer-term follow-up data were presented that give credence to this approach, which ignores how social ostracism is grounded in transphobia arising from society as a whole.

There was no mention of mental health impacts in the studies on barriers to transition-related healthcare. What is known, however, is that TGD affirmative practices are associated with positive mental health outcomes. ${ }^{53}$ Austin et $a l^{\tilde{p}^{3}}$ reported that transgender cognitive behaviour therapy showed good preliminary evidence of effectiveness, with decreases in depression over a 3-month follow-up period.

\section{RESEARCH CONSIDERATIONS AND CONCLUDING REMARKS}

This review identified a research gap within the conversion therapy discourse, namely the prevalence and characteristics of such treatments of TGD people, their current form and their mental health consequences. Primary research in TGD identified people would seem to be the best way forward to answer these questions. However, such research would need to cast a wide net to capture the experiences of conversion therapies. For example, besides talking treatments, verbal and physical harassment by healthcare professionals in the care of TGD youth and adults, and gatekeeping in terms of waiting lists and referral processing, should be investigated with mental health outcomes as a primary concern. Any research focusing on conversion therapies would need to use a retrospective method due to the ethics surrounding conversion practices. Qualitative studies of the experience of conversion therapy should be undertaken, particularly to identify the voluntary and involuntary paths TGD people took towards any conversion therapy, and their experiences during such treatments and beyond. Despite our finding evidence of access barriers to transition-related healthcare for TGD people, longitudinal research from a prospective cohort is needed to examine (1) how often and how soon access barriers are experienced and (2) the mental health impacts of being denied appropriate transition-related healthcare

To an extent our findings are reassuring, in that explicit attempts at conversion therapy seem to be less common than was the case in LGB people, and erecting barriers to transition-related healthcare were also not common. However, our results only concern peer-reviewed published literature and thus we cannot exclude the possibility of conversion treatments and bars on accessing treatment in day-to-day clinical practice. Thus, our results alert practitioners to the possibilities of such practice and how it is inappropriate. Our recommendation is to investigate the topic further using primary research methods in a cross section of TGD people in order to understand more about TGD conversion experiences and specific access barriers to transition-related healthcare.

Contributors MK conceived the original idea for the review, which was refined with the other authors. TW derived the search terms and strategy with assistance from BC and MK. TW undertook the review, screening and assessment of papers with assistance from $B C$ and MK on inclusion of papers. TW wrote the first draft of the paper and all authors contributed to the final version.

Funding The authors have not declared a specific grant for this research from any funding agency in the public, commercial or not-for-profit sectors.

Competing interests Not declared.

Patient consent for publication Not required.

Provenance and peer review Not commissioned; externally peer reviewed.

Data sharing statement No technical appendix, statistical code, and/or dataset available from the Dryad repository, as this review does not have raw data to share.

Open access This is an open access article distributed in accordance with the Creative Commons Attribution Non Commercial (CC BY-NC 4.0) license, which permits others to distribute, remix, adapt, build upon this work non-commercially, and license their derivative works on different terms, provided the original work is properly cited, appropriate credit is given, any changes made indicated, and the use is non-commercial. See: http://creativecommons.org/licenses/by-nc/4.0/.

\section{REFERENCES}

1. Saewyc EM. Respecting variations in embodiment as well as gender: Beyond the presumed 'binary' of sex. Nurs Inq 2017;24:e12184.

2. Conron KJ, Scott G, Stowell GS, et al. Transgender health in Massachusetts: results from a household probability sample of adults. Am J Public Health 2012;102:e20171683.

3. Reed B, Rhodes S, Schofield P, et al. Gender variance in the UK: Prevalence, incidence, growth and geographic distribution. 2011 http://worldaa1.miniserver.com/ gires/assets/Medpro-Assets/ GenderVarianceUK-report.pdf

4. Ellis SJ, Bailey L, McNeil J. Trans people's experiences of mental health and gender identity services: a UK Study. J Gay Lesbian Ment Health 2015;19:4-20.

5. Arcelus J, Bouman WP, Van Den Noortgate W, et al. Systematic review and meta-analysis of prevalence studies in transsexualism. Eur Psychiatry 2015;30:807-15.

6. Chen M, Fuqua J, Eugster EA. Characteristics of referrals for gender dysphoria over a 13-Year Period. J Adolesc Health 2016;58:369-71.

7. Dhejne C, Van Vlerken R, Heylens G, et al. Mental health and gender dysphoria: A review of the literature. Int Rev Psychiatry 2016;28:44-57.

8. England NHS, Scotland NHS. The Scottish Government... et al. Memorandum of understanding on conversion therapy in the UK. 2015 https://www.psychotherapy.org.uk/wp-content/uploads/2016/ 09/Memorandum-of-understanding-on-conversion-therapy.pdf.

9. Strudwick P. Trans therapists sign open letter to mental health body over conversion therapy [internet]. 2017 https://www.buzzfeed.com/ patrickstrudwick/trans-therapists-sign-open-letter-to-mental-healthbody-over?utm_term=.kf7QXgXL3z\#.byBQlelZ2R (Accessed 20 Jul 17).

10. Substance Abuse and Mental Health Services Administration, Ending Conversion Therapy. Supporting and Affirming LGBTQ Youth. HHS Publication No. (SMA) 15-4928. Rockville, MD: Substance Abuse and Mental Health Services Administration, 2015.

11. Haldeman DC. The practice and ethics of sexual orientation conversion therapy. J Consult Clin Psychol 1994;62:221-7.

12. Throckmorton W. Efforts to modify sexual orientation: a review of outcome literature and ethical issues. Journal of Mental Health Counseling 1998;20:283.

13. Dehlin JP, Galliher RV, Bradshaw WS, et al. Psychosocial correlates of religious approaches to same-sex attraction: a mormon perspective. J Gay Lesbian Ment Health 2014;18:284-311.

14. Dehlin JP, Galliher RV, Bradshaw WS, et al. Sexual orientation change efforts among current or former LDS church members. J Couns Psychol 2015;62:95-105.

15. Premier Christianity. Why I voted against the 'conversion therapy' ban and transgender motions at Synod. 2017 https://www. premierchristianity.com/Blog/Why-l-voted-against-the-conversion- 
therapy-ban-and-transgender-motions-at-Synod(acessed on 30.11.2018).

16. Fox F. Leelah alcorn's suicide: conversion therapy is child abuse. 2015 http://time.com/3655718/leelah-alcorn-suicide-transgendertherapy/ (accessed on 9.08.2017).

17. Shear MD. Obama calls for end to 'conversion therapies for gay and transgender youth. The New York Times, 2015.

18. Kaiser Health News. Can delaying puberty help transgender kids? 2016 https://www.thedailybeast.com/can-delaying-puberty-helptransgender-kids (Accessed on 13 Jan 2018).

19. Anderson R. New paper says puberty blockers aren't the answer to gender confusion. 2017 http://dailysignal.com/2017/06/20/ new-paper-says-puberty-blockers-arent-answer-gender-confusion/ (Accessed on 13 Jan 2018).

20. Growing Up Transgender. The end of the 'desistance' myth. 2017 https://growinguptransgender.wordpress.com/2017/12/03/the-endof-the-desistance-myth/ (Accessed on 13 Jan 2018).

21. Wallien MS, Cohen-Kettenis PT. Psychosexual outcome of gender-dysphoric children. J Am Acad Child Adolesc Psychiatry 2008;47:1413-23.

22. Zucker KJ. On the "natural history" of gender identity disorder in children. J Am Acad Child Adolesc Psychiatry 2008;47:1361-3.

23. Drummond KD, Bradley SJ, Peterson-Badali M, et al. A followup study of girls with gender identity disorder. Dev Psychol 2008;44:34-45.

24. Temple Newhook J, Pyne J, Winters K, et al. A critical commentary on follow-up studies and "desistance" theories about transgender and gender-nonconforming children. International Journal of Transgenderism 2018;19:212-24.

25. Steensma TD, Biemond R, de Boer F, et al. Desisting and persisting gender dysphoria after childhood: a qualitative follow-up study. Clin Child Psychol Psychiatry 2011;16:499-516.

26. Steensma TD, Cohen-Kettenis PT. Gender transitioning before puberty? Arch Sex Behav 2011;40:649-50.

27. Serovich JM, Craft SM, Toviessi P, et al. A systematic review of the research base on sexual reorientation therapies. J Marital Fam The 2008;34:227-38.

28. Valdes F. Queers, sissies, dykes, and tomboys: deconstructing the conflation of "sex," "gender," and "sexual orientation" in euroamerican law and society (Doctoral dissertation, Stanford Law School) 1994.

29. Riessman CK. Narrative analysis: University of Huddersfield, 2005.

30. The Joanna Briggs Institute. Joanna briggs institute reviewers' manual: 2016 edition. Australia: The Joanna Briggs Institute, 2016

31. Critical Appraisal Skills Programme. CASP Qualitative research. 2017 http://www.casp-uk.net/casp-tools-checklists (cited 7 Jan 2018).

32. Critical Appraisal Skills Programme. CASP Cohort research. 2017 http://www.casp-uk.net/casp-tools-checklists (cited 7 Jan 2018).

33. Zients AB. Andy. A boy who thought he needed to be a girl. Psychoanal Study Child 2003;58:19-34.

34. Gilmore K. Gender identity disorder in a girl: insights from adoption. $J$ Am Psychoanal Assoc 1995;43:39-59.

35. Marks IM, Mataix-Cols D. Four-year remission of transsexualism after comorbid obsessive-compulsive disorder improved with selfexposure therapy. Case report. Br J Psychiatry 1997;171:389-90.

36. Zucker KJ, Wood H, Singh D, et al. A developmental, biopsychosocial model for the treatment of children with gender identity disorder. J Homosex 2012;59:369-97.
37. Gridley SJ, Crouch JM, Evans Y, et al. Youth and caregiver perspectives on barriers to gender-affirming health care for transgender youth. J Adolesc Health 2016;59:254-61.

38. Vance SR, Halpern-Felsher BL, Rosenthal SM. Health care providers comfort with and barriers to care of transgender youth. J Adolesc Health 2015;56:251-3.

39. Snelgrove JW, Jasudavisius AM, Rowe BW, et al. "Completely out-at-sea" with "two-gender medicine": a qualitative analysis of physician-side barriers to providing healthcare for transgender patients. BMC Health Serv Res 2012;12:110.

40. Bancroft J, Marks I. Treatment of sexual deviations: electric aversion therapy of sexual deviations. Proc Roy Soc Med 1968;61:30-2.

41. Marks I, Gelder M, Bancroft J. Sexual deviants two years after electric aversion. Br J Psychiatry 1970;117:173-85.

42. Flentje A, Heck NC, Cochran BN. Experiences of ex-ex-gay individuals in sexual reorientation therapy: reasons for seeking treatment, perceived helpfulness and harmfulness of treatment, and post-treatment identification. J Homosex 2014;61:1242-68.

43. Kattari SK, Walls NE, Speer SR. Differences in experiences of discrimination in accessing social services among transgender/ gender nonconforming individuals by (Dis)ability. J Soc Work Disabil Rehabil 2017;16:116-40.

44. Costa AB, da Rosa Filho HT, Pase PF, et al. Healthcare needs of and access barriers for brazilian transgender and gender diverse people. $\mathrm{J}$ Immigr Minor Health 2018;20:115-23.

45. White Hughto JM, Murchison GR, Clark K, et al. Geographic and individual differences in healthcare access for u.s. transgender adults: a multilevel analysis. LGBT Health 2016;3:424-33.

46. Safer JD, Coleman E, Feldman J, et al. Barriers to healthcare for transgender individuals. Curr Opin Endocrinol Diabetes Obes 2016;23:168-71.

47. Jaffee KD, Shires DA, Stroumsa D. Discrimination and delayed health care among transgender women and men: implications for improving medical education and health care delivery. Med Care 2016;54:1010-6.

48. Cruz TM. Assessing access to care for transgender and gender nonconforming people: a consideration of diversity in combating discrimination. Soc Sci Med 2014;110:65-73.

49. Hussey W. Slivers of the journey: the use of photovoice and storytelling to examine female to male transsexuals' experience of health care access. J Homosex 2006;51:129-58.

50. de Vries AL, McGuire JK, Steensma TD, et al. Young adult psychological outcome after puberty suppression and gender reassignment. Pediatrics 2014;134:696-704.

51. Transgender History in the United States. A special unabridged version of a book chapter from Trans Bodies, Trans Selves: Transgender History in the United States. https://www.umass.edu/ stonewall/sites/default/files/Infoforandabout/transpeople/genny_ beemyn transgender history in the united states.pdf

52. Hakeem A, Črnčec R, Asghari-Fard $\bar{M}$, et al. Development and validation of a measure for assessing gender dysphoria in adults: the gender preoccupation and stability questionnaire. International Journal of Transgenderism 2016;17:131-40.

53. Austin A, Craig SL, D'Souza SA. An AFFIRMative cognitive behavioral intervention for transgender youth: Preliminary effectiveness. Professional Psychology: Research and Practice 2018;49:1-8. 